\title{
Prevalence of Intestinal Helminthiases and Associated Factors among Pregnant Women Attending Antenatal Clinic of Nigist Eleni Mohammed Memorial Hospital, Hossana, Southern Ethiopia
}

\author{
Dawit Jember Tesfaye ${ }^{1 *}$, Wassie Gebi Beshir², Tariku Dejene ${ }^{3}$, Tsegaye Tewelde ${ }^{4}$ \\ ${ }^{1}$ Department of Clinical Nursing Hossana College of Health Sciences, Hossana, Ethiopia \\ ${ }^{2}$ Adama Medical College, Adama, Ethiopia \\ ${ }^{3}$ Department of Biostatistics, College of Public Health and Medical Sciences, Jimma University, Jimma, Ethiopia \\ ${ }^{4}$ Department of Epidemiology, College of Public Health and Medical Sciences, Jimma University, Jimma, \\ Ethiopia \\ Email: *devanhijember@gmail.com, wassieki@yahoo.com, tariku dejene@yahoo.com, \\ tsegaye.tewelde@yahoo.com
}

Received 26 June 2015; accepted 11 July 2015; published 17 July 2015

Copyright (C) 2015 by authors and OALib.

This work is licensed under the Creative Commons Attribution International License (CC BY). http://creativecommons.org/licenses/by/4.0/

(c) (i) Open Access

\section{Abstract}

Background: In the developing world, young women, pregnant women, and their infants and children frequently experience repeated helminthic infection, that lead to anemia, intrauterine growth retardation and low birth weight. Despite the difference in distribution of helminths infection within a country, the information on prevalence of intestinal Helminthiases and its associated risk factors among pregnant women in the area is lacking. Therefore, this study aimed to determine the prevalence of intestinal helminthic infection among pregnant women attending antenatal care (ANC) clinic of Nigist Eleni Mohammed Memorial Hospital Hossana, Southern Ethiopia. Method and Materials: A hospital based cross sectional study design was employed. Two hundred and fifty eight pregnant women attending the hospital ANC clinic from October 1 to 30, 2013 were included in the study. Structured questionnaire was used to collect data using interviewer administered technique. For parasitological examination, formol ether concentration technique was used to detect helminthes from clinical specimen. Data were analyzed using SPSS for windows version 16.0. Statistical tests were performed at the level of significance of $5 \%$. Multivariate logistic regression analysis was done to identify the significant risk factors. Result: The overall prevalence of any helminths infection was $\mathbf{2 9 . 5 \%}$. A. lumbricoides was the predominant helminths infection, detected in $\mathbf{1 0 . 1 \%}$ of pregnant women. There is positive association between family size and helminths

\footnotetext{
"Corresponding author.
} 
infection $[\mathrm{AOR}=4.45 ; 95 \% \mathrm{CI} ;(1.98,10.02)]$, presence of water body in the vicinity of residence [AOR = 3.39; 95\% CI = 1.20, 9.57], habit of walking bare foot $[\mathrm{AOR}=3.23 ; 95 \% \mathrm{CI}$; $1.28,8.15)]$, unprotected source $[\mathrm{AOR}=8.71,95 \% \mathrm{CI} ;(1.60,27.39)]$ and rural residence $[\mathrm{AOR}=3.64,95 \% \mathrm{CI}$; $(1.33,9.97)]$. Monthly income $>1500$ Eth. Birr $[\mathrm{AOR}=0.48 ; 95 \% \mathrm{CI} ;(0.23,0.99)]$ and living in thatched roof house $[\mathrm{AOR}=0.24,95 \% \mathrm{CI} ;(0.06,0.89)]$ were found to have negative association with helminths infection. Conclusion: The present study showed high prevalence of intestinal helminthes among pregnant women in the study area. Stool exam should be routinely performed during antenatal care follow-up. Public health measures should continue to emphasize the importance of environmental and personal hygiene as well as provide and monitor the quality of drinking water aiming to obtain a better quality of life.

\title{
Keywords
}

\author{
Intestinal Helminthiasis, Pregnant Women, Antenatal Care, Risk Factors
}

Subject Areas: Nursing, Public Health

\section{Introduction}

More than two billion people are infected with helminth parasites worldwide [1]. The greatest numbers occur in sub-Saharan Africa, the Americas, China and East Asia [2]. In 2005, it was estimated that $26.7 \%$ of pregnant women and 37.7 million (25.5\%) reproductive age group women in SSA are infected with hookworm [3]. Studies conducted in different parts of Ethiopia detected more than $40 \%$ of prevalence of helminthes infection among pregnant women [4] [5].

Most parts of Ethiopia are suitable for the transmission of soil transmitted helminthes (STHs), except parts of Somali and Afar regions where the annual mean temperature is too high for transmission [6]. Parasitic helminthic infections are the second most predominant causes of outpatient morbidity in the country. Ethiopia has one of the lowest quality drinking water supplies and latrine coverage in the world. The effect of altitude, urbanization, irrigation, and resettlement on the distribution of intestinal parasitism was depicted in previous studies [7].

Both nutritional deficiencies and parasitic infection, specifically hookworm and malaria infection, contribute most to anemia. In fact, hookworm infections are recognized as the leading cause of pathologic blood loss in tropical and subtropical countries [8]. Hookworm infections contribute to anemia by causing blood loss directly through ingestion and mechanical damage of the mucosa, and indirectly, by affecting the supply of nutrients necessary for erythropoiesis [9]-[12].

Ethiopia is one of the high burden countries in Africa for infection of Hookworm, Ascariasis Trichuriasis, Schistosomiasis, Teaniasis and Hymenolopsis nana [13]-[15]. Intestinal parasitic infections, especially due to the helminthes, have been associated with anemia in pregnant women [16]. Anemia is thought to be the major contributory cause of death in $20 \%-40 \%$ of these maternal deaths [8], and iron deficiency anemia accounts $16 \%$ $20 \%$ of all maternal deaths [11]. Besides, hookworm infection induces total energy, protein, and possible folate and zinc deficiencies. Evidence also suggests that both iron deficiency anemia and, separately, hookworm infection, will inhibit appetite and resulting in low pregnancy weight gain and intrauterine growth retardation (IUGR), followed by low birth weight (LBW) and adverse birth outcomes [17]-[21].

Determinants of helminth infection depend on the route of transmission and lifecycle of the helminth. Commonly helminth infections are related to hygiene, sanitation and for some species, environmental conditions required for the intermediate hosts or for a free-living soil-dwelling stage. Immunological responses according to the species vary with age, but long-term chronic infection over several years has been observed for many species. Environmental conditions like humidity, temperature, other climatic factors and presence of water affect the distribution of helminthes [22] [23]. For pregnant women the risk factors can be categorized as background: demographic and socioeconomic variables, intermediate: HIV status, gravidity and type of water source, and the proximate risk factors include prior anthelmintic treatment, crowding in the household, exposure to lake or rivers through swimming or bathing, home toilet facilities and walking barefoot [24]. 
Periodical deworming to eliminate infecting worms, health education to prevent reinfection, improved sanitation to reduce soil contamination with infective eggs and safe and effective medicines are available to control infection [2]. Mass drug administration (MDA) programs for STHs are most often directed at school-aged children as they are the population group most at risk of acquiring heavy infection and developing associated morbidity. Other at risk groups are preschool children, women of childbearing age (including pregnant women in the second and third trimesters and breastfeeding women), and adults in certain high-risk occupations, such as tea-pickers or miners [2]. However, some MDA programs are directed at whole communities in highly endemic areas [23].

Despite high burden of helminthes infection in Ethiopia, the control is not well targeted [25] [26]. Since, there is difference of distribution of helminths infection within a country and in different geographic setup, the information on prevalence of intestinal helminthiases and also the associated risk factors especially in pregnant women in the area is lacking. Therefore, this study aimed to determine the prevalence of intestinal helminthic infection and its associated risk factors among pregnant women's attending ANC clinic of Nigist Eleni Mohamed Memorial Hospital (NEMM), Hosanna, South Ethiopia.

\section{Methods and Materials}

\subsection{Study Design and Setting}

Hospital based cross sectional study was conducted at Nigist Eleni Mohamed Memorial Hospital ANC clinicfrom October 1 to 30, 2013. The hospital is located in Hossana Town, Hadiya Zone, Southern Nation's Nationalities and People's Regional state (SNNPR). The town is $232 \mathrm{~km}$ far from Addis Ababa, the capital city of Ethiopia and $194 \mathrm{~km}$ from the regional capital, Hawassa. The total area of the zone is 374.2 Square kilometer 3542.66 sq. $\mathrm{km}$ and comprises ten districts, one town administration, 305 rural and 24 urban kebeles with a total population of 1,506,733. Expected Pregnant Women are 54,242 (3.6\%) of the population.

\subsection{Selection of the Study Participants}

The source population was all pregnant women attending ANC clinic of Nigist Eleni Mohamed Memorial Hospital. The study population consisted of selected pregnant women attending ANC clinic at Nigist Eleni Mohamed Memorial Hospital during the study period and who were resident in Hossana town and surrounding kebeles and not having received an the helminthic treatment for the last 6 months. The required sample size was computed using single population proportion with finite population correction formula with the assumption of $64.7 \%$ prevalence rate of intestinal helminthic infection among pregnant women [27], Critical value at 95\% level of confidence $(Z=1.96)$, Margin of error (5\%). The calculated sample size yield 234 and adding $10 \%$ non-response rate the final sample size was calculated to be 258 . A systematic random sampling technique was used to select the study subjects. The average number of pregnant women attending the hospital ANC clinic per day is 20 and per month 440 . The sampling interval $(K)$ was calculated to be 1.7 . Therefore, every $2^{\text {nd }}$ pregnant women attended the hospital ANC clinic were included in the study.

\subsection{Data Collection}

Structured questionnaire was used to collect data using interviewer administered technique which was developed after reviewing related studies. The questionnaire has three sections that included socio-demographic information, personal, and environmental characteristics.

Questionnaire was prepared in English and translated into Amharic and translated back into English to check its consistency. The Amharic version questionnaire was used for data collection after pretesting on $10 \%$ of the actual sample size at Hosanna health center. Some clarifications and corrections on the questionnaire were made after the pre-testing.

Unique code was given for each questionnaire and laboratory request format. After interview, the participants were requested to give stool sample in clean dry bottle. Similar codes were written on the bottles with the questionnaires and the laboratory request formats. Faecal samples were collected using wet preparation. A drop of fresh physiological saline was placed on a clean slide. Using an applicator sticks, $1 \mathrm{~g}$ of stool was emulsified in $7 \mathrm{ml}$ of $10 \%$ for mol saline and it was kept for 10 minutes for fixation. Straining through wire gauze, the filtrate was added to $3 \mathrm{ml}$ of ether and centrifuged at $2000 \mathrm{rpm}$ for 2 minutes and it was allowed to settle. The supernatant 
was removed and a wet mount made of the deposit used to look for parasites. The preparations were covered with cover slip and examined under the microscope for the presence or absence of intestinal parasite, larvae or ova. The preparation was observed under the microscope using $10 \times$ and $40 \times$ objectives respectively with the condenser iris closed sufficiently to give good contrast [28]. All specimens were examined for the presence of adult worms, or segment, the consistency, color, presence of mucus and blood.

\subsection{Data Processing \& Analysis}

Data was entered and analyzed using SPSS version 16 computer software. Summary results were presented by frequency tables and graphs. Bivariate analysis was performed to check the existence of association between dependent and independent variables. Independent variables with P-value of $<0.25$ in bivariate analysis were considered for multivariate logistic regressions. P-value less than 0.05 was used as cut off point for presence of statistical significance.

\subsection{Quality Assurance}

Training was provided to data collectors for three days about the objective, process of data collection and standard operating procedure. Pre-testing of the data collection instruments were conducted at Hosanna town health center ANC clinic before actual data collection. Standard operating procedure (SOP) was used for every laboratory procedures. Closer supervision was undertaken during data collection. Specimens were selected randomly and reanalyzed for cross checking the accuracy of laboratory results.

\subsection{Ethical Consideration}

Ethical clearance was obtained from Ethical Review Board of Jimma University, College of Public Health and Medical Sciences. Permission paper was sought from Hadiya Zone Health Department and Nigist Eleni Mohammed Memorial Hospital. Verbal informed consent was obtained from each study participants and participant's right to refuse participation in the study or withdraw at any time during the course of the interview was respected. Maximum effort was made to maintain confidentiality of the information obtained. Pregnant women with positive result were referred to the clinician in ANC clinic for anthelminthic treatment as per guideline.

\section{Results}

\subsection{Socio-Demographic Characteristics of the Respondents}

A total of 258 consented pregnant women during the follow up visit to the antenatal care were enrolled in this study. The mean age $( \pm \mathrm{SD})$ of the attendants was $25.4( \pm 3.8)$ years ranging between 19 - 35 years. Four (1.6\%) were below 18 years old, and six (2.3\%) were 36 years and above. One hundred ninety six (76\%) of the women came from urban. Out of 258 attendants 127 (49.2\%) attended above secondary school, 79 (30.6\%) were primary and junior grades and $52(20.2 \%)$ can't read and write. One hundred thirty three (51.6\%) pregnant women were house wife, 89 (34.5\%) were employed, 28 (10.9\%) merchant or self-employed and 8 (3\%) were students. Two hundred forty nine (96.5\%) were married. The mean family monthly income of the respondents was 1828.8 Eth. Birr (Range from 200 - 5000 Eth. Birr) (Table 1).

\subsection{Personal and Environmental Characteristics}

Among all 212 (82.2\%) of the respondents live in houses made from corrugated sheet. Hundred thirty seven (53.1\%) of the respondents were used water from piped line inside the compound and 99 (38.4\%) were used piped water outside their compound. A significant number of the respondents (95\%) live in households that have toilet facility. Also a high proportion of respondents (95.3) wash their hands after toilet. Most (98.8\%) of them also responded to wash hands before preparing food. Nearly one fourth (24.0\%) of the respondents were live around or near lakes or any other water bodies. Ninety (35.3\%) were without separate house or room for animals. Habit of walking barefoot accounted for 91 (29.5\%) and 208 (80.6\%) of the respondents wear sandal frequently. Most of the respondents 202 (78.3\%) were not used traditional medicine in the last six months while 56 (21.7\%) were used traditional medicine. More than half 147 (57.0\%) of the respondents were multigravida and 158 (61.2\%) were in the second trimester of pregnancy (Table 2). 
Table 1. Bivariate logistic regression result of intestinal helminthes infection by socio-demographic characteristic among pregnant women, NigistEleni Mohammed Memorial Hospital, Hossana, South Ethiopia, 2013.

\begin{tabular}{|c|c|c|c|c|c|}
\hline \multirow{2}{*}{ Characteristics } & \multicolumn{2}{|c|}{ Helminthes } & \multirow{2}{*}{ Total (N) } & \multirow{2}{*}{ COR (95\% CI) } & \multirow{2}{*}{ P-value } \\
\hline & No (N/\%) & Yes (N/\%) & & & \\
\hline \multicolumn{6}{|l|}{ Age } \\
\hline$<18$ & $3(75)$ & $1(25)$ & 4 & 1 & \\
\hline $19-25$ & 113 (81.9) & $25(18.1)$ & 138 & $0.66(0.07,6.65)$ & 0.730 \\
\hline$>25$ & $66(36.3)$ & $50(65.8)$ & 116 & $2.27(0.23,22.50)$ & 0.483 \\
\hline \multicolumn{6}{|l|}{ Place of residence } \\
\hline Urban & $160(81.2)$ & 37 (18.8) & 197 & 1 & \\
\hline Rural & $22(36.1)$ & 39 (63.9) & 61 & $7.66(4.07,14.44)$ & 0.000 \\
\hline \multicolumn{6}{|l|}{ Marital status } \\
\hline Married & $174(69.9)$ & $75(30.1)$ & 249 & 1 & \\
\hline Single/Widowed & 8 (88.9) & $1(11.1)$ & 9 & $0.29(0.04,2.36)$ & 0.247 \\
\hline \multicolumn{6}{|l|}{ Ethnicity } \\
\hline Hadiya & 109 (69) & $49(31)$ & 158 & 1 & \\
\hline Kembata & 29 (78.4) & $8(21.6)$ & 37 & $0.61(0.26,1.43)$ & 0.261 \\
\hline Amhara & 17 (56.7) & $13(43.3)$ & 30 & $1.70(0.77,3.77)$ & 0.191 \\
\hline Silte & 8 (88.9) & $1(11.1)$ & 9 & $0.28(0.034,2.28)$ & 0.234 \\
\hline Guraghe & $16(76.2)$ & $5(23.8)$ & 21 & $0.69(0.24,2.005)$ & 0.501 \\
\hline \multicolumn{6}{|l|}{ Education } \\
\hline Can’t read and write & 17 (32.7) & $35(67.3)$ & 52 & 1 & \\
\hline 1 - 6 grade & $26(70.3)$ & $11(29.7)$ & 37 & $0.205(0.08,0.51)$ & 0.001 \\
\hline 7 - 8 grade & 36 (85.7) & $6(14.3)$ & 42 & $0.08(0.03,0.23)$ & 0.000 \\
\hline$\geq 9$ grade & $103(81.1)$ & $24(18.9)$ & 127 & $0.12(0.055,0.24)$ & 0.000 \\
\hline \multicolumn{6}{|l|}{ Religion } \\
\hline Protestant & $127(73.8)$ & $45(26.2)$ & 172 & 1 & \\
\hline Muslim & $20(87.0)$ & $3(13.0)$ & 23 & $0.423(0.12,1.49)$ & 0.181 \\
\hline Orthodox & 30 (55.6) & $24(44.4)$ & 54 & $2.26(1.19,4.26)$ & 0.012 \\
\hline Catholic & $5(62.5)$ & 3 (37.5) & 8 & $1.69(0.39,7.37)$ & 0.483 \\
\hline \multicolumn{6}{|l|}{ Income } \\
\hline$\leq 1500$ & 86 (63.7) & 49 (36.3) & 135 & 1 & \\
\hline$>1500$ & $96(78)$ & $27(22)$ & 123 & $0.49(0.28,0.86)$ & 0.012 \\
\hline \multicolumn{6}{|l|}{ Family size } \\
\hline$\leq 2$ & 81 (84.4) & $15(15.6)$ & 96 & 1 & \\
\hline$\geq 3$ & $101(62.3)$ & $61(37.7)$ & 162 & $3.26(1.73,6.16)$ & 0.000 \\
\hline \multicolumn{6}{|l|}{ Occupation } \\
\hline Employed & $58(65.2)$ & 31 (34.8) & 89 & 1 & \\
\hline House wife & $92(69.2)$ & $41(30.8)$ & 133 & $0.83(0.47,1.47)$ & 0.532 \\
\hline Merchant/farmer/student & 32 (88.9) & $4(11.1)$ & 36 & $0.23(0.08,0.72)$ & 0.012 \\
\hline
\end{tabular}


Table 2. Bivariate logistic regression result of intestinal helminthes infection by personal and Environmental characteristics among pregnant women, Nigist Eleni Mohammed Memorial Hospital, Hossana, South Ethiopia, 2013.

\begin{tabular}{|c|c|c|c|c|c|}
\hline \multirow{2}{*}{ Characteristics } & \multicolumn{2}{|c|}{ Helminthes } & \multirow{2}{*}{ Total (N) } & \multirow{2}{*}{${ }^{*} \mathrm{COR}(95 \% \mathrm{CI})$} & \multirow{2}{*}{ P-value } \\
\hline & No (N/\%) & Yes (N/\%) & & & \\
\hline \multicolumn{6}{|l|}{ Type of House } \\
\hline Corrugated sheet & $163(76.9)$ & $49(23.1)$ & 212 & 1 & \\
\hline Thatched & $19(41.3)$ & 27 (58.7) & 46 & $4.73(2.42,9.22)$ & 0.001 \\
\hline \multicolumn{6}{|l|}{ Water source } \\
\hline Pipe in the compound & $111(81)$ & $26(19)$ & 137 & 1 & \\
\hline Pipe outside compound & $66(66.7)$ & $33(33.3)$ & 99 & $2.13(1.17,3.88)$ & 0.013 \\
\hline Unprotected source & $5(22.7)$ & 17 (77.3) & 22 & $14.51(4.90,42.94)$ & 0.001 \\
\hline \multicolumn{6}{|l|}{ Gravida } \\
\hline Premigravida & $80(72.1)$ & $31(27.9)$ & 111 & 1 & \\
\hline Multigravida & $102(69.4)$ & 45 (30.6) & 147 & $0.878(0.51,1.51)$ & 0.640 \\
\hline \multicolumn{6}{|l|}{ Trimester } \\
\hline First & $8(100)$ & $0(0)$ & 8 & 0.00 & 0.999 \\
\hline Second & $104(65.8)$ & $54(34.2)$ & 158 & $1.65(0.92,2.95)$ & 0.090 \\
\hline Third & $70(76.1)$ & $22(23.9)$ & 92 & 1 & \\
\hline \multicolumn{6}{|c|}{ Frequency of soap use after toilet } \\
\hline Daily & $164(73.2)$ & $60(26.8)$ & 224 & 1 & \\
\hline Infrequently & $14(63.6)$ & $8(36.4)$ & 22 & $1.56(0.62,3.91)$ & 0.340 \\
\hline \multicolumn{6}{|l|}{$\begin{array}{l}\text { Presence of water body in the } \\
\text { vicinity of households }\end{array}$} \\
\hline Yes & $31(50)$ & $31(50)$ & 62 & 1 & \\
\hline No & $151(77)$ & $45(23)$ & 196 & $0.29(0.16,0.54)$ & 0.001 \\
\hline \multicolumn{6}{|l|}{$\begin{array}{l}\text { Traditional Medicine taken } \\
\text { In the last 6th month }\end{array}$} \\
\hline Yes & $26(46.4)$ & 30 (53.6) & 56 & 1 & \\
\hline No & $156(77.2)$ & $46(22.8)$ & 202 & $0.27(0.14,0.47)$ & 0.001 \\
\hline \multicolumn{6}{|l|}{ Animal live in the House } \\
\hline Yes & $54(59.3)$ & 37 (40.7) & 91 & 1 & \\
\hline No & $128(76.6)$ & 39 (23.4) & 167 & $0.44(0.26,0.77)$ & 0.004 \\
\hline \multicolumn{6}{|l|}{ Habit of walking barefoot } \\
\hline Yes & $33(43.4)$ & $43(56.6)$ & 76 & 1 & \\
\hline No & $149(81.9)$ & 33 (18.1) & 182 & $0.17(0.09,0.31)$ & 0.001 \\
\hline \multicolumn{6}{|l|}{ Wear sandal frequently } \\
\hline Yes & $154(74)$ & $54(26)$ & 208 & 1 & \\
\hline No & $28(56)$ & $22(44)$ & 50 & $2.24(1.18,4.24)$ & 0.013 \\
\hline
\end{tabular}

${ }^{*}$ Crude odds ratio. 


\subsection{Prevalence of Intestinal Helminths}

The overall prevalence of any helminths infection was 76 (29.5\%). In this study five species of intestinal helminths were identified in the stool samples, with Ascaris lumbricoides was the predominant intestinal helminths infection, detected in 26 (10.1\%) of pregnant women, and Hookworm was the second most frequently detected intestinal parasite with prevalence of 18 (7.0\%). Trichuris trichuria, Taenia species and H.nana were detected in $9(3.5 \%), 3(1.2 \%)$ and $2(0.8 \%)$ of the respondents respectively. More than one fifth (22.6\%) of pregnant women had a single infection, while $6.9 \%$ had double infections. Ascaris with Hook worm co-infection were found in 13 (5.0\%) of the respondents and 5 (1.9\%) were with Ascaris lumbricoides and Trichuria co-infection (Table 3).

\subsection{Factors Associated with Intestinal Helminthiasis among Pregnant Women}

Using backward multiple logistic regression analysis, participants with greater than three family size were about five times more likely to have intestinal helminths than those from family size of less than or equal to two [AOR $=4.45 ; 95 \% \mathrm{CI}=(1.98,10.02)]$. Pregnant women who earn monthly income of $>1500$ Eth. birr were less likely to be infected by intestinal helminthes than those pregnant who earn $\leq 1500$ Eth. birr $[\mathrm{AOR}=0.48,95 \% \mathrm{CI}$; $(0.23,0.99)]$. Pregnant women who came from rural area were more likely infected by intestinal helminthes [AOR = 3.64; 95\% CI, $(1.33,9.97)]$ than pregnant women who came from rural area. Pregnant women living in thatched houses were less likely infected by intestinal helminthes than those pregnant living in houses with corrugated sheet $[\mathrm{AOR}=0.24,95 \% \mathrm{CI} ;(0.06,0.89)]$. Pregnant women who used unprotected source were about nine times more likely to be infected by intestinal helminthes than those pregnant who used Piped line water [AOR $=8.71,95 \%$ CI; $(1.60,27.39)]$. Pregnant women who live around or near lakes or any other water bodies were about three times more likely to be infected by intestinal helminthes $[\mathrm{AOR}=3.39$; $95 \% \mathrm{CI}=(1.202$, 9.573)]. Those pregnant who have habit of walking bare foot were three times more likely to have intestinal helminths $[\mathrm{AOR}=3.23 ; 95 \% \mathrm{CI}=(1.28,8.15)]$ than pregnant women who wear shoes (Table 4).

\section{Discussion}

This study showed the prevalence of intestinal helminthic infection among pregnant women was $29.5 \%$. This finding is lower than the studies conducted among pregnant women in Southern Ethiopia 64.7\% [4], rural Kenya 76.2\% [29], Venezuela 73.9\% [30], Gabon 64\% [27], and Ugandan 68.3\% [31]. This low prevalence in this study might be due to geographic difference, time gap where those studies were done averagely four years ago but nowadays there is a better awareness of about intestinal parasite infection and their cause. Even though a

\begin{tabular}{|c|c|c|}
\hline Intestinal parasites & No (\%) & ${ }^{*} \mathrm{~N}=258$ \\
\hline A. lumbricoides & $26(10.1)$ & \\
\hline Hookworm spp. & $18(7.0)$ & \\
\hline T. trichuria & $9(3.5)$ & \\
\hline Taenia spp. & $3(1.2)$ & \\
\hline H. nana & $2(.8)$ & \\
\hline Ascaris with Hook worm & $13(5.0)$ & \\
\hline Ascaris with Trichuria & $5(1.9)$ & \\
\hline Total prevalence of any helminthes infection & $76(29.5)$ & \\
\hline No ova or helminthic parasite seen & $182(70.5)$ & \\
\hline
\end{tabular}

\footnotetext{
${ }^{*}$ Total number of study participants.
} 
Table 4. Multivariate logistic regression model predicting intestinal helminths infection among pregnant women, Nigist Eleni Mohammed Memorial Hospital, Hossana, South Ethiopia, 2013.

\begin{tabular}{|c|c|c|c|c|c|}
\hline \multirow{2}{*}{ Characteristics } & \multicolumn{2}{|c|}{ Helminthes } & \multirow{2}{*}{ Total (N) } & \multirow{2}{*}{ "AOR (95\% CI) } & \multirow{2}{*}{ P-value } \\
\hline & No (N/\%) & Yes (N/\%) & & & \\
\hline \multicolumn{6}{|l|}{ Family size } \\
\hline$\leq 2$ & $81(84.4)$ & $15(15.6)$ & 96 & 1 & \\
\hline$\geq 3$ & $101(62.3)$ & $61(37.7)$ & 162 & $4.45(1.98,10.02)$ & 0.001 \\
\hline \multicolumn{6}{|l|}{ Income (in Birr) } \\
\hline$\leq 1500$ & $86(63.7)$ & 49 (36.3) & 135 & 1 & \\
\hline$>1500$ & $96(78)$ & $27(22)$ & 123 & $0.48(0.23,0.99)$ & 0.048 \\
\hline \multicolumn{6}{|l|}{ Place of residence } \\
\hline Urban & $160(81.2)$ & 37 (18.8) & 97 & 1 & \\
\hline Rural & $22(36.1)$ & 39 (63.9) & 61 & $3.64(1.33,9.97)$ & 0.012 \\
\hline \multicolumn{6}{|l|}{ Type of House } \\
\hline Corrugated sheet & 163 (76.9) & $49(23.1)$ & 212 & 1 & \\
\hline Thatched & 19 (41.3) & 27 (58.7) & 46 & $0.24(0.06,0.89)$ & 0.033 \\
\hline \multicolumn{6}{|l|}{ Water source } \\
\hline Piped in the compound & $111(81)$ & $26(19)$ & 137 & 1 & \\
\hline \multicolumn{6}{|l|}{ Piped outside } \\
\hline Compound & $66(66.7)$ & 33 (33.3) & 99 & $1.12(0.49,2.58)$ & 0.790 \\
\hline Unprotected source & $5(22.7)$ & 17 (77.3) & 22 & 8.71 (1.60, 27.39) & 0.012 \\
\hline \multicolumn{6}{|l|}{ Presence of water body } \\
\hline Yes & $31(50)$ & $31(50)$ & 62 & $3.39(1.20,9.6)$ & 0.021 \\
\hline No & $151(77)$ & $45(23)$ & 196 & 1 & \\
\hline \multicolumn{6}{|l|}{ Habit of walking barefoot } \\
\hline Yes & 33 (43.4) & 43 (56.6) & 76 & $3.23(1.28,8.15)$ & 0.013 \\
\hline No & 149 (81.9) & 33 (18.1) & 182 & 1 & \\
\hline
\end{tabular}

*Adjusted odd ratio.

study conducted at Butajira, Ethiopia is on mothers and their infants, the overall prevalence of any STH infection being $43.5 \%$ [32].

The predominant parasite detected in this study was Ascaris lumbricoides $10.1 \%$ which is similar with studies conducted in Ethiopia and other low income countries [4] [27] [29] [30] [33]. An overall prevalence of co-infection in this study was 7\%, of which Ascaris lumbricoides and Hookworm co-infection was the dominant 5.0\%. Similarly finding 6.6\% was reported in a study conducted in Butajira, South Ethiopia [32]. Also the study from Uganda reported 9.7\% co-infection but with a Hookworm and S. stercoralis combination [24].

Women living in rural areas had a significantly higher prevalence of hookworm infection (63.9\%) compared with women living in urban (18.8\%) area which is similar with study conducted by Larocque. R et al. in 2005 in which higher prevalence of hookworm infection among rural women compared with women living in periurban areas [34].

In this study, pregnant women with habit of walking bare foot have three times more likely to have intestinal helminthes than those who do not have the habit. This finding is comparable with study of Larocque, R. et al. 
(2005) in which those who do not wear at least sandal either inside or outside of their houses had higher hookworm prevalence than women wearing sandals [34]. In other studies which assess the anemia status of pregnant women, there was a statistical significance difference between anemia and shoe wearing habit [4] [35]. Most rural pregnant women walk barefoot; even those women who have shoe do not wear regularly. They wear shoe when they come to town for antenatal care and for marketing. Walking barefoot may predispose to hookworm infection because the infective stage of the parasite develops in soil.

Pregnant women living in corrugated sheet had increased risk of infection compared to those living in thatched roof which is different from other studies [32]. The discrepancy might be because of the small sample size for those subjects coming from rural area.

Infections with at least one intestinal helminth species were associated with the use of an unprotected water source. This finding is in line with the study conducted in rural Kenya [29] in which infection was also associated with lack of household treatment of drinking water. However, water source or treatment was not statistically significantly associated with any geohelminth species [29].

Pregnant women who live around or near lakes or any other water bodies were about three times more likely to be infected by intestinal helminthes. Even though the detected helminthes do not have a life cycle or developmental stage in water as seen in Shistosomas, the presence of lake or river might be important in contamination and dissemination of the parasites. One example could be peoples have exposure to these water bodies for washing purpose and may also be contaminated with feces and sewage. Like in many other developing countries, intestinal parasites are widely distributed in Ethiopia largely due to the low level of environmental and personal hygiene, contamination of food and drinking water that results from improper disposal of human excreta [36].

This study focused only on the presence of helminthes infection and its associated factors. Prevalence is seldom used as the only measure to assess the epidemiological situation for that helminth infection, because morbidity is associated with the number of worms infecting the host (i.e., the worm burden) rather than the absence or presence of infection. Prevalence is commonly combined with worm burden (also referred to as the "intensity of infection"), which is commonly measured by the number of eggs per gram (EPGs) of feces for intestinal helminths [2] [5]. Other limitations of this study include the small sample size and use of a single stool specimen to assess infection status, which may have underestimated geohelminth burden.

\section{Conclusion and Recommendation}

The present study showed high prevalence of intestinal helminthes among pregnant women in the study area. The prevalent species of intestinal helminthes identified in this study were A. lumbricoides and Hookworm species.

Infections with at least one intestinal helminth species among pregnant women were associated with the use of an unprotected water source, living around or near lakes or any other water bodies and also those with habit of walking bare foot were more likely to have intestinal helminths. The other predictors of helminths infection in pregnant women identified from multivariate analysis were family size, monthly income, and type of house remained significant factors.

Even though guidelines set the importance of stool examination during antenatal follow-up, the practice is still poor and should be routinely performed during antenatal care follow-up. Public health measures should continue to emphasize the importance of environmental and personal hygiene as well as provide and monitor the quality of drinking water aiming to obtain a better quality of life. Deworming strategies may play imperative role in reducing helminth infection among pregnant women. Health education about prevention of contamination, particularly among rural residents, is vital. Moreover large scale longitudinal study is needed to determine the effect of helminthiases in pregnant with estimate of worm burden (intensity of infection).

\section{Acknowledgements}

The authors acknowledged Hossana College of Health Sciences for supporting this research through provision of laboratory materials and equipment's and duplication of the questionnaire.

\section{Competing Interests}

The authors declared that there are no competing interests. 


\section{Authors' Contributions}

Wassie Gebi Beshir, Dawit Jember Tesfaye, Tariku Dejene and Tsegaye Teweldeparticipated from the conception to the end of this paper.

\section{References}

[1] Harhay, M.O., Horton, J., Olliaro, P.L., et al. (2010) Epidemiology and Control of Human Gastrointestinal Parasites in Children. Expert Review of Anti-Infective Therapy, 8, 219-234. http://dx.doi.org/10.1586/eri.09.119

[2] World Health Organization (WHO) (2012) Soil-Transmitted Helminth Infections [Document on Theinternet]. http://www.who.int/mediacentre/factsheets/fs366/en/index.html

[3] Brooker, S., Hotez, P.J. and Bunday, D.A.P. (2008) Hookworm-Related Anaemia among Pregnant Women: A Systematic Review. PLoS Neglected Tropical Diseases, 2, e291. http://dx.doi.org/10.1371/journal.pntd.0000291

[4] Tadege, B. (2009) Determinants of Anaemia in Pregnant Women with Emphasis on Intestinal Helminthic Infection at Bushulo Health Center Southern Ethiopia. Addis Ababa University: Libraries Electronic, Thesis and Dissertations Database, AAU-ETD.

[5] Getachew, M., et al. (2012) Anaemia and Associated Risk Factors among Pregnant Women in Gilgel Gibe Dam Area, Southwest Ethiopia. Parasites \& Vectors, 5, 296. http://dx.doi.org/10.1186/1756-3305-5-296

[6] Pullan, L.R. and Brooker, S.J. (2012) The Global Limits and Population at Risk of Soil Transmitted Helminth Infections in 2010. Parasites \& Vectors, 5, 81. http://dx.doi.org/10.1186/1756-3305-5-81

[7] Jemaneh, L. (1998) Comparative Prevalence of Some Common Intestinal Helminthic Infections in Different Altitudinal Regions in Ethiopia. Ethiopian Medical Journal, 36, 1-8.

[8] Viteri, F.E. (1994) The Consequences of Iron Deficiency and Anemia in Pregnancy. Advances in Experimental Medicine and Biology, 352, 127-139. http://dx.doi.org/10.1007/978-1-4899-2575-6_10

[9] Bundy, D.A., Chan, M.S. and Savioli, L. (1995) Hookworm Infection in Pregnancy. Transactions of the Royal Society of Tropical Medicine \& Hygiene, 89, 521-522. http://dx.doi.org/10.1016/0035-9203(95)90093-4

[10] King, C. (2004) Re-Gauging the Cost of Chronic Helminthic Infection: Meta-Analysis of Disability-Related Outcomes in Endemic Schistosomiasis. Lancet, 368, 1106-1118.

[11] Crompton, D.W.T. (2000) The Public Health Importance of Hook-Worm Disease. Parasitology, 121, 39-50. http://dx.doi.org/10.1017/S0031182000006454

[12] Pawlowski, Z.S., Schad, G.A. and Stott, G.J. (1991) Hookworm Infection and Anemia: Approaches to Prevention and Control. World Health Organization, Geneva.

[13] Hotez, P.J. and Kamath, A. (2009) Neglected Tropical Diseases in Sub-Saharan Africa: Review of Their Prevalence, Distribution, and Disease Burden. PLoS Neglected Tropical Diseases, 3, e412. http://dx.doi.org/10.1371/journal.pntd.0000412

[14] Tadesse, Z., Hailemariam, A. and Kolaczinski, J.H. (2008) Potential for Integrated Control of Neglected Tropical Diseases in Ethiopia. Transactions of the Royal Society of Tropical Medicine and Hygiene, 102, 213-214. http://dx.doi.org/10.1016/j.trstmh.2007.09.005

[15] Steinmann, P., Keiser, J., Bos, R., Tanner, M. and Utzinger, J. (2006) Schistosomiasis and Water Resources Development: Systematic Review, Meta-Analysis, and Estimates of People at Risk. The Lancet Infectious Diseases, 6, 411-425. http://dx.doi.org/10.1016/S1473-3099(06)70521-7

[16] Steketee, R.W. (2003) Pregnancy, Nutrition and Parasitic Diseases. The Journal of Nutrition, 133, 1661S-1667S.

[17] Nurdia, D.S., Sumarni, S., Suyoko, Hakim, M. and Winkvist, A. (2001) Impact of Intestinal Helminth Infection on Anemia and Iron Status during Pregnancy: A Community Based Study in Indonesia. The Southeast Asian Journal of Tropical Medicine and Public Health, 32, 14-22.

[18] Stephenson, L.S., Latham, M.C. and Ottesen, E.A. (2000) Malnutrition and Parasitic Helminth Infections. Parasitology, 121, 23-38. http://dx.doi.org/10.1017/S0031182000006491

[19] World Health Organization (2002) Prevention and Control of Schistosomiasis and Soil-Transmitted Helminthiasis: Report of a WHO Expert Committee. World Health Organization, Geneva.

[20] Le Hesran, J.Y., Akiana, J., Ndiaye, EL H.M., Dia, M., Senghor, P., et al. (2004) Severe Malaria Attack is Associated with High Prevalence of Ascaris lumbricoides Infection among Children in Rural Senegal. Transactions of the Royal Society of Tropical Medicine and Hygiene, 98, 397-399. http://dx.doi.org/10.1016/j.trstmh.2003.10.009

[21] Nacher, M., Singhasivanon, P., Traore, B., Vannaphan, S., Gay, F., et al. (2002) Helminth Infections Are Associated with Protection from Cerebral Malaria and Increased Nitrogen Derivatives Concentrations in Thailand. The American Journal of Tropical Medicine and Hygiene, 66, 304-309. 
[22] Brooker, S. and Clements, A.C. (2009) Spatial Heterogeneity of Parasite Co-Infection: Determinants and Geostatistical Prediction at Regional Scales. International Journal for Parasitology, 39, 591-597. http://dx.doi.org/10.1016/j.ijpara.2008.10.014

[23] Lustigman, S., Prichard, R.K., Gazzinelli, A., Grant, W.N., Boatin, B.A., et al. (2012) A Research Agenda for Helminth Diseases of Humans: The Problem of Helminthiases. PLoS Neglected Tropical Diseases, 6, e1582. http://dx.doi.org/10.1371/journal.pntd.0001582

[24] Woodburn, P.W., Muhangi, L., Hillier, S., Ndibazza, J., Namujju, P.B., et al. (2009) Risk Factors for Helminth, Malaria, and HIV Infection in Pregnancy in Entebbe, Uganda. PLoS Neglected Tropical Diseases, 3, e473. http://dx.doi.org/10.1371/journal.pntd.0000473

[25] Liese, B., Rosenberg, M. and Schratz, A. (2010) Programmes, Partnerships, and Governance for Elimination and Control of Neglected Tropical Diseases. The Lancet, 375, 67-76. http://dx.doi.org/10.1016/S0140-6736(09)61749-9

[26] Federal Ministry of Health (2004) Guidelines for the Enhanced Outreach Strategy (EOS) for Child Survival Interventions. Addis Ababa, Ethiopia.

[27] Adegnikaet, A.A., et al. (2010) Epidemiology of Parasitic Co-Infections during Pregnancy in Lambaréné, Gabon. Tropical Medicine \& International Health, 15, 1204-1209. http://dx.doi.org/10.1111/j.1365-3156.2010.02598.x

[28] Cheesbrough, M. (2009) District Laboratory Practice in Tropical Countries Part 1. 2nd Edition, Cambridge University Press, Cambridge, 195-216.

[29] Van Eijk, A.M., Lindblade, K.A., Odhiambo, F., Peterson, E., Rosen, D.H., et al. (2009) Geohelminth Infections among Pregnant Women in Rural Western Kenya: A Cross-Sectional Study. PLoS Neglected Tropical Diseases, 3 , e370. http://dx.doi.org/10.1371/journal.pntd.0000370

[30] Alfonso, J., Rodríguez-Morales, et al. (2006) Intestinal Parasitic Infections among Pregnant Women in Venezuela. Infectious Diseases in Obstetrics and Gynecology, 2006, 1-5. http://dx.doi.org/10.1155/idog/2006/23125

[31] Fuseini, G., et al. (2010) Parasitic Infections and Anaemia during Pregnancy in the Kassena-Nankana District of Northern Ghana. Journal of Public Health and Epidemiology, 2, 48-52.

[32] Belyhun, Y., et al. (2010) Prevalence and Risk Factors for Soil-Transmitted Helminth Infection in Mothers and Their Infants in Butajira, Ethiopia: A Population Based Study. BMC Public Health, 10, 21. http://dx.doi.org/10.1186/1471-2458-10-21

[33] Alli, J.A., et al. (2011) Prevalence of Intestinal Nematode Infection among Pregnant Women Attending Antenatal Clinic at the University College Hospital, Ibadan, Nigeria. Advances in Applied Science Research, 2, 1-13.

[34] Larocque, R., Easapia, M., Gotuzzo, E. and Gyorkos, T. (2005) Relationship between Intensity of Soil-Transmitted Helminth Infections and Anemia during Pregnancy. The American Journal of Tropical Medicine and Hygiene, 73 , 783-789.

[35] Belachew, T. and Yosef, L. (2006) Risk Factors for Anaemia among Pregnant Women Attending Antenatal Clinic at Jimma University Hospital. Ethiopian Medical Journal, 44, 211-220.

[36] Kumie, A. and Ali, A. (2005) An Overview of Environmental Health Status in Ethiopia with Particular Emphasis to Its Organization, Drinking Water and Sanitation: A Literature Survey. Ethiopian Journal of Health Development, 19, 89-103. http://dx.doi.org/10.4314/ejhd.v19i2.9977 